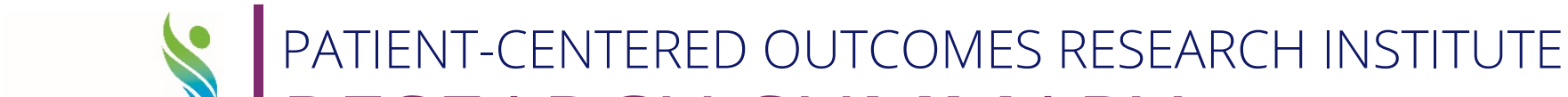 pcori). RESEARCH SUMMARY
}

\section{Does a Stress Management Program for African-American Parents Increase Asthma Symptom-Free Days for Their Children? - The BEAMS Study}

Principal investigator

Stephen J. Teach, MD, MPH
Organization

Children's Research Institute

\section{What was the research about?}

Asthma is a common illness in children that can make it hard to breathe. African-American children have more hospital visits and die at higher rates from asthma than white children. High stress levels in parents of children with asthma can increase symptoms, such as wheezing, and related problems for children.

In this study, the research team wanted to see if helping African-American parents manage stress could increase the number of days their children had no asthma symptoms. The team compared children of parents who took part in a stress management program with children of parents who weren't in the program. All children in the study received usual asthma care that included three months of services to help coordinate care.

\section{What were the results?}

After six months, children in both groups had more days without asthma symptoms. The two groups had a similar increase in days without symptoms.

However, at 12 months, children whose parents took part in the stress management program had a greater increase in days without symptoms compared with children whose parents weren't in the program.

\section{Who was in the study?}

The study included 217 parent-child pairs from Washington, DC. All children and parents were African American. Children had asthma, were ages 4 to 12 , and had public insurance. The average age of children was 7, and 61 percent were boys. The average age of parents was 38, and 92 percent were women.

\section{What did the research team do?}

The research team assigned parents by chance to either take part in the six-month stress management program or not. The stress management program had three main parts:

- One-on-one sessions with a wellness coach. In the first three months of the program, parents met with a trained wellness coach four times in person or by phone. During these sessions, the wellness coach taught parents ways to handle stress.

- Group sessions. Parents could go to group sessions with other parents twice a month. Group sessions reviewed information from the one-onone sessions and offered time for parents to talk with each other.

- Text or phone messages. The research team sent parents weekly text messages about stress management. The text messages had information from the sessions and links to more information. 
Parents who couldn't get text messages got the same information by phone.

Parents in the stress management program also had access to a website for the program.

All children in the study received usual asthma care. With this care, parents learned how to treat their children's asthma and manage their children's care.

The research team interviewed parents when the study started and again 6 and 12 months later.

Parents of children with asthma, doctors, social workers, and experts in asthma and stress management gave input to the research team during the study.

\section{What were the limits of the study?}

This study included children who were African American and had public insurance. Results may differ for children with other backgrounds.

Future research could test the program with more people and follow up for longer than 12 months.

\section{How can people use the results?}

Health clinics treating children with asthma can use these results when considering ways to support children with asthma and their parents.

To learn more about this project, visit www.pcori.org/Teach190. 